\title{
Morphological Alterations of Penicillium chrysogenum Caused by Carbon Dioxide
}

\author{
By CHESTER S. HO* AND MARK D. SMITH \\ Biochemical Engineering Laboratory, Department of Chemical Engineering, State University of \\ New York at Buffalo, Buffalo, New York 14260, USA
}

(Received 30 December 1985; revised 19 June 1986)

\begin{abstract}
Scanning electron microscopic studies showed that the morphology of Penicillium chrysogenum Thom in fermentation cultures changed in response to changes in $\mathrm{CO}_{2}$ concentration. At influent $\mathrm{CO}_{2}$ partial pressures between $0.03 \%$ (air) and $8 \%$, the predominant morphological form was filamentous, whereas at $15 \% \mathrm{CO}_{2}$, swollen and stunted hyphae predominated, and a significant quantity of spherical or yeast-like cells was observed.
\end{abstract}

\section{INTRODUCTION}

The morphology of submerged mycelial organisms can be affected by a variety of environmental variables. Pirt \& Callow (1959) showed that pellet formation and growth of the normal filamentous forms of Penicillium chrysogenum in a continuous submerged fermentation were determined by the $\mathrm{pH}$ of the medium. Average hyphal branch length was $200 \mu \mathrm{m}$ for mycelia grown at $\mathrm{pH} 6.0$ compared with $20 \mu \mathrm{m}$ at $\mathrm{pH} \mathrm{7.4}$. At pH 7.4 large numbers of swollen yeast-like cells were observed, indicating the beginning of pellet formation. These morphological alterations attributable to $\mathrm{pH}$ were reversible. When $P$. chrysogenum was grown in glucoselimited chemostat cultures at $25^{\circ} \mathrm{C}$ and a dilution rate of $0.09 \mathrm{~h}^{-1}$, hyphal branch length varied with $\mathrm{pH}$, attaining a maximum value of $110 \mu \mathrm{m}$ at $\mathrm{pH} 6.0$ compared with that of $45 \mu \mathrm{m}$ at $\mathrm{pH} 8.0$ (Miles \& Trinci, 1983). Variation of the diameters of hyphae grown at different $\mathrm{pH}$ values was not significant. The authors suggested that $\mathrm{pH} 6.0$ is optimal for hyphal extension of $P$. chrysogenum.

Cell morphology is affected by the nitrogen source (Pirt \& Callow, 1959). Replacement of ammonium sulphate by corn steep liquor increased hyphal length, reduced the frequency of hyphal branching and prevented formation of swollen cells at $\mathrm{pH} \mathrm{7.4.} \mathrm{Nutrient} \mathrm{formulation} \mathrm{is}$ also important. Morton (1961) observed that conidiation of Penicillium griseofulvum Dierckx was rapidly induced in a medium containing a high concentration of glucose but lacking assimilable nitrogen. However, $P$. chrysogenum remained vegetative upon nitrogen exhaustion. Specific growth rate also affects cell morphology of $P$. chrysogenum. Righelato et al. (1968) found that vegetative growth occurred at a specific growth rate of $0.023-0.075 \mathrm{~h}^{-1}$. As the growth rate was increased within this range, the occurrence of pellets and swollen cells increased. Conidiation occurred at specific growth rates below $0.014 \mathrm{~h}^{-1}$.

Ho \& Smith (1986) demonstrated that exposure of $P$. chrysogenum cultures to a range of moderate to high dissolved $\mathrm{CO}_{2}$ concentrations retarded antibiotic production, decreased growth rate and caused marked morphological changes. This paper describes the effect of $\mathrm{CO}_{2}$ concentration on the mycelial morphology of $P$. chrysogenum.

Abbreviation: SEM, scanning electron microscopy. 


\section{METHODS}

The sporulation culture. Penicillium chrysogenum Thom, strain Wisconsin 54-1255 (ATCC 28089), was used. This strain is capable of producing up to $1 \mathrm{~g}$ penicillin per litre of fermentation medium. Activated spores were grown on agar slants (Ho \& Smith, 1986) for 7-10 d. These mature surface cultures were stored at $4{ }^{\circ} \mathrm{C}$ and remained stable for up to three months at this temperature.

Inoculum development. An inoculum for the fermentation culture was prepared by removing spores from mycelia by mild agitation with sterile glass beads in $300 \mathrm{ml}$ distilled water. Spore suspensions contained approximately $10^{6}$ spores $\mathrm{ml}^{-1}$ as determined with a haemocytometer (Fisher Scientific).

Bench-scale process. A Biostat S laboratory fermentation system (12.51 capacity) was used (Ho \& Smith, 1986). Growth medium (Ho \& Smith, 1986) was added to the vessel aseptically. The $\mathrm{pH}$ was adjusted to 6.5 by addition of concentrated $\mathrm{NH}_{4} \mathrm{OH}$ or a solution of $1 \mathrm{M}-\mathrm{H}_{2} \mathrm{SO}_{4}$ and $1.5 \mathrm{M}-\left(\mathrm{NH}_{4}\right)_{2} \mathrm{SO}_{4}$; glucose was sterilized separately. $\mathrm{pH}$ was measured with an Ingold steam-sterilizable $\mathrm{pH}$ electrode and controlled with a home-made $\mathrm{pH}$ controller. Dissolved $\mathrm{CO}_{2}$ was monitored with a steam-sterilizable $\mathrm{CO}_{2}$ electrode (Ingold Electrodes). Effluent $\mathrm{CO}_{2}$ concentration was measured with an Esterline Angus infrared gas analyser. Dissolved $\mathrm{O}_{2}$ was measured with an Ingold dissolved $\mathrm{O}_{2}$ electrode.

Unless otherwise mentioned, the following conditions were held constant: temperature, $25^{\circ} \mathrm{C}$; rotational speed, 950 r.p.m.; air flow rate, $81 \mathrm{~min}^{-1}$ ( 1 vol. per culture vol. per min); glucose concentration, $40 \mathrm{~g} \mathrm{l}^{-1}$; and $\mathrm{pH}, 6.5$. The influent gas was air with various proportions of $\mathrm{N}_{2}$ replaced by equivalent amounts of $\mathrm{CO}_{2}$ to give influent $\mathrm{CO}_{2}$ partial pressures of $0.03 \%$ (air), $8.2 \%, 15 \%$ and $20 \%$. The influent gas stream was fed to the fermentation vessel at constant temperature, pressure and flow rate for each fermentation run.

Specimen preparation for scanning electron microscopy (SEM). The following procedure was developed to fix and dehydrate the mycelial specimens for SEM studies. The morphological state of the cells in these specimens compared well with that of cells observed by light microscopy.

A $5 \mathrm{ml}$ sample from the culture vessel was added to $25 \mathrm{ml} 2 \%(\mathrm{v} / \mathrm{v})$ glutaraldehyde solution at the same osmolarity as the culture medium. The glutaraldehyde solution was decanted from settled cells after incubation at $4{ }^{\circ} \mathrm{C}$ for $2 \mathrm{~h}$. Cells were then resuspended in a buffer solution of $30.5 \mathrm{~g} \mathrm{KH}_{2} \mathrm{PO}_{4}$ in $100 \mathrm{ml} \mathrm{H} \mathrm{H}_{2} \mathrm{O}$, and stored at $4{ }^{\circ} \mathrm{C}$.

Fixed cells $(5 \mathrm{ml})$ were injected through a Nucleopore filter (pore size $0.8 \mu \mathrm{m}$ ). A pre-filter was used to remove any particulate materials that might be present in the reagents and to protect the cells. All subsequent treatments were made through this pre-filter by injection. Portions $(25 \mathrm{ml})$ of ethanol, $10 \%, 25 \%, 50 \%, 75 \%$ and $100 \%(\mathrm{v} / \mathrm{v})$ in $\mathrm{H}_{2} \mathrm{O}$, were injected through the filter in successive washings, each of about 5 min duration. Freon $113(50 \%$, v/v) in ethanol $(40 \mathrm{ml})$ was then injected through the specimen for $10 \mathrm{~min}$, followed by $40 \mathrm{ml} 100 \%$ Freon 113 for a further $10 \mathrm{~min}$. The specimen was dried with injected air and stored in a desiccator.

The specimen was frozen very quickly in Freon cooled in liquid $\mathrm{N}_{2}$, and either stored in liquid $\mathbf{N}_{2}$ or moved to a cold stage in a vacuum coating unit. The specimen was introduced into a freeze-drying apparatus consisting of a vacuum system with a cold surface close to the specimen.

\section{RESULTS AND DISCUSSION}

Lyophilized spores of $P$. chrysogenum are shown in Fig. 1. Characteristically, these are the asexual conidiospores that are produced on agar slant cultures. The diameter of the spores was $5.5 \mu \mathrm{m}$. Hyphae of $P$. chrysogenum grown for $48 \mathrm{~h}$ under control conditions (no $\mathrm{CO}_{2}$ added to the influent air) are shown in Fig. 2. The mycelium was composed of a network of long, thin, diffuse hyphae, whose average thickness was $2.0 \mu \mathrm{m}$. Characteristically, hyphae grew from a central branch, and the hyphal tips were smooth and round, indicating an actively growing site (Righelato et al., 1968; Trinci \& Righelato, 1970; Collinge et al., 1978; Miles \& Trinci, 1983). It is believed that any deviance from this morphological form would indicate altered metabolism.

Fig. 3 shows a hypha from mycelium grown for $48 \mathrm{~h}$ at an influent $\mathrm{CO}_{2}$ concentration of $8.2 \%$. The predominant morphological form was filamentous. The hyphal branching frequency was greater than that observed in the control experiment; this would presumably result in a high growth rate as the quantity of actively growing sites was increased. The diameter of the hyphae was $2 \cdot 0-2 \cdot 5 \mu \mathrm{m}$. Other morphological changes started to become apparent at this $\mathrm{CO}_{2}$ concentration. An altered hyphal tip is shown in Fig. 4. Such swelling of the hyphal tips was accompanied by an increased hyphal branching frequency near the tip.

$P$. chrysogenum grown for $48 \mathrm{~h}$ with an influent $\mathrm{CO}_{2}$ concentration of $15 \%$ had a morphology similar to that of yeast cells and spores (Fig. 5). Some filamentous growth was noted, however; this originated from spores, $6 \cdot 0-7 \cdot 0 \mu \mathrm{m}$ in diameter, which resembled the spherical or yeast-like forms present in the culture. It is possible that the spherical forms were simply stunted spores. 


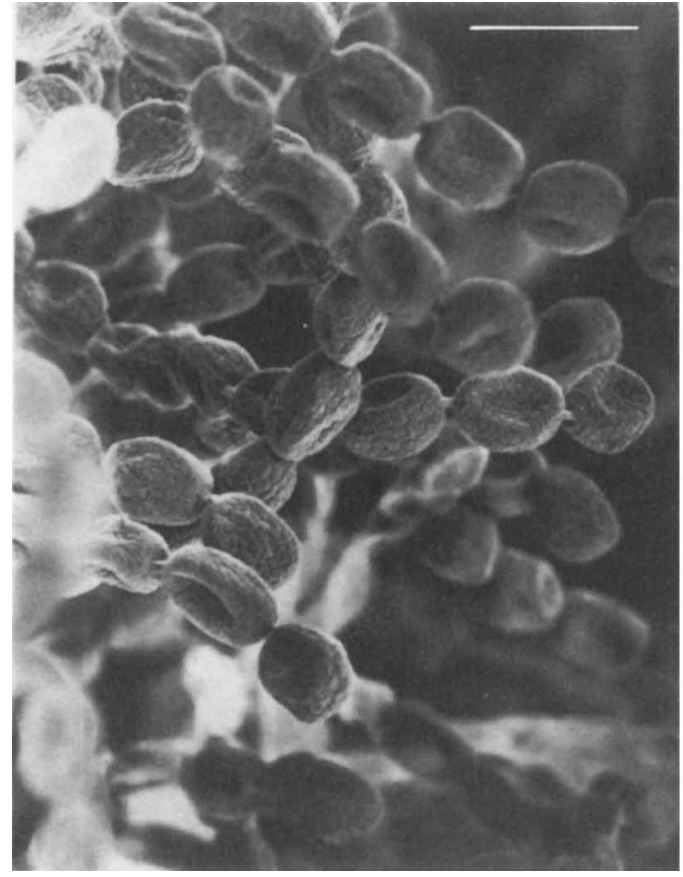

Fig. 1

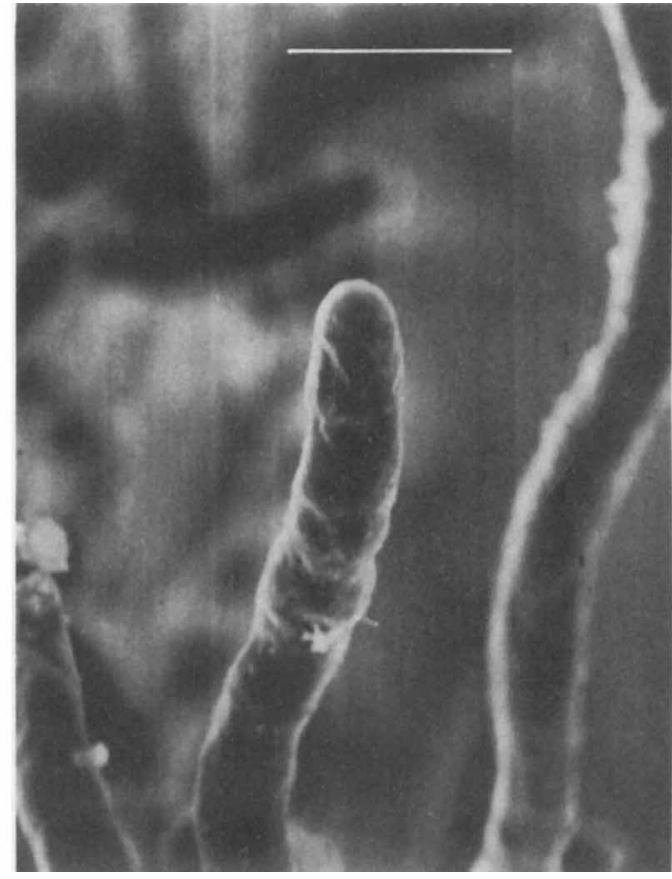

Fig. 2

Fig. I SEM micrograph of lyophilized spores. Bar, $5 \mu \mathrm{m}$.

Fig. 2. SEM micrograph of a hyphal tip from a culture grown for $48 \mathrm{~h}$ without additional $\mathrm{CO}_{2}$. Bar, $5 \mu \mathrm{m}$.

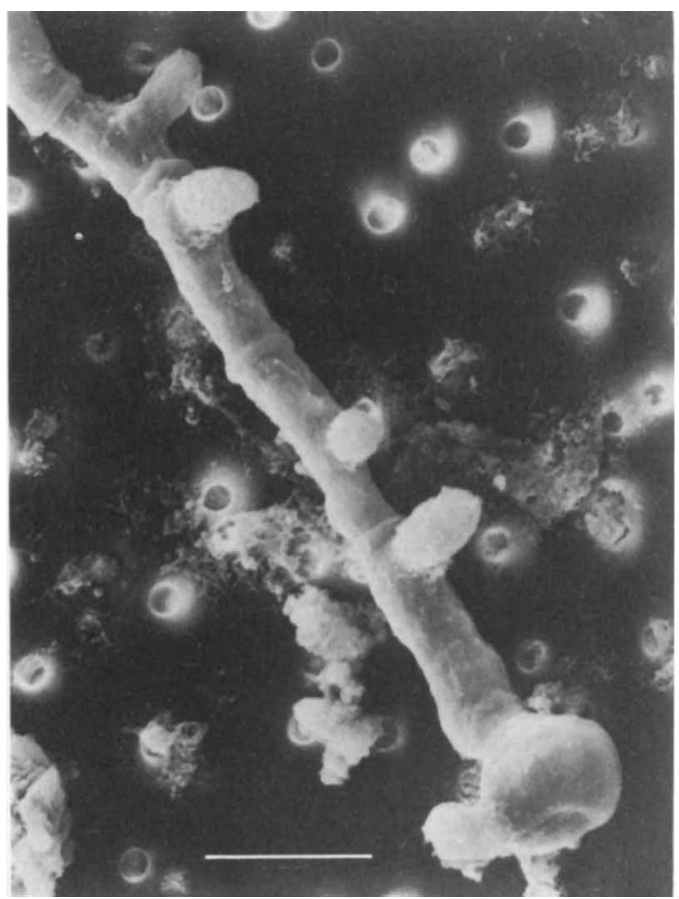

Fig. 3

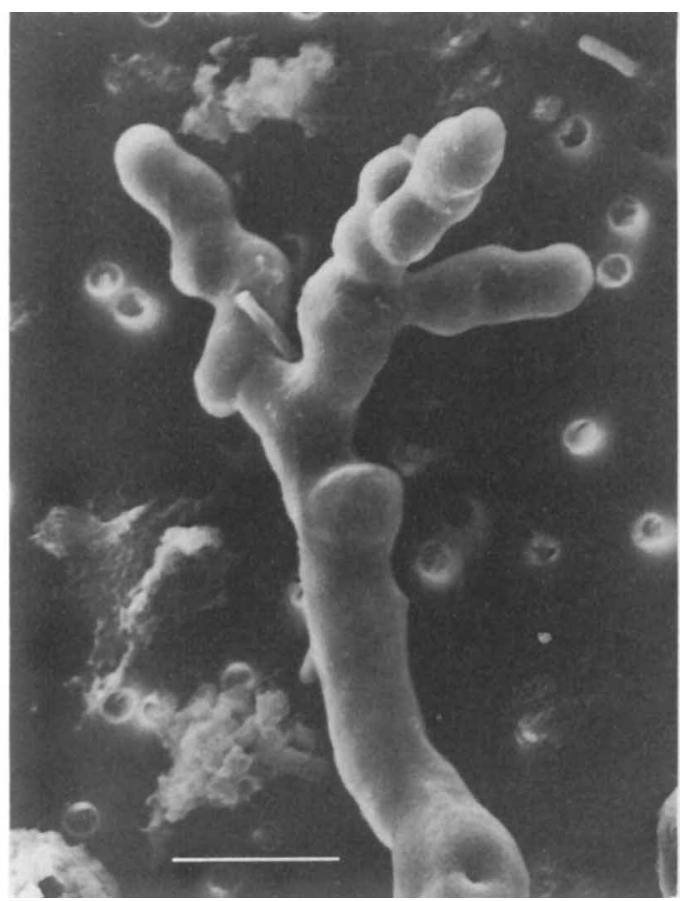

Fig. 4

Fig. 3. SEM micrograph of hypha from a culture grown for $48 \mathrm{~h}$ under $8.2 \% \mathrm{CO}_{2}$. Bar, $5 \mu \mathrm{m}$.

Fig. 4. SEM micrograph of hypha from a culture grown for $48 \mathrm{~h}$ under $8 \cdot 2 \% \mathrm{CO}_{2}$, showing abnormal tip morphology. Bar, $5 \mu \mathrm{m}$. 


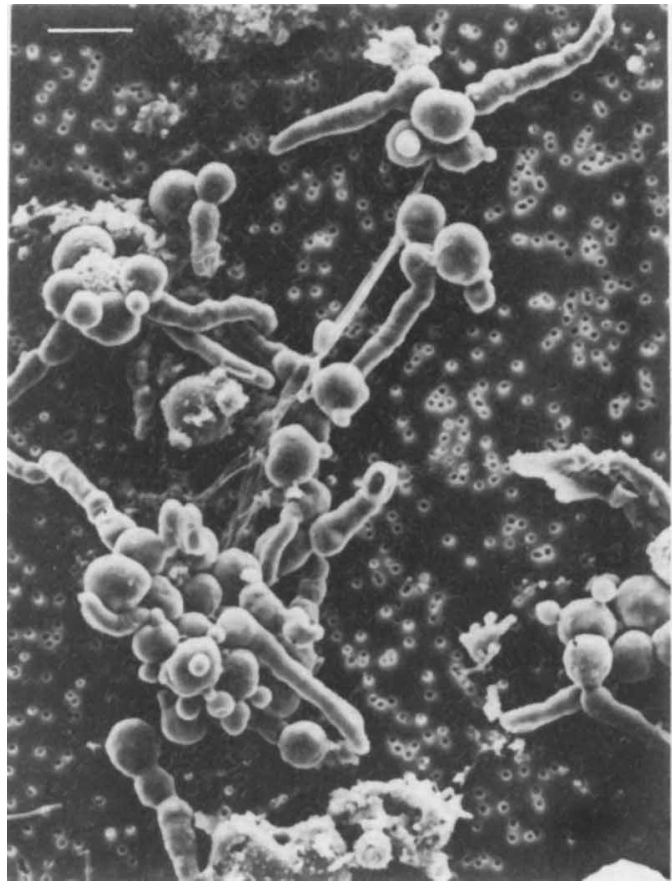

Fig. 5

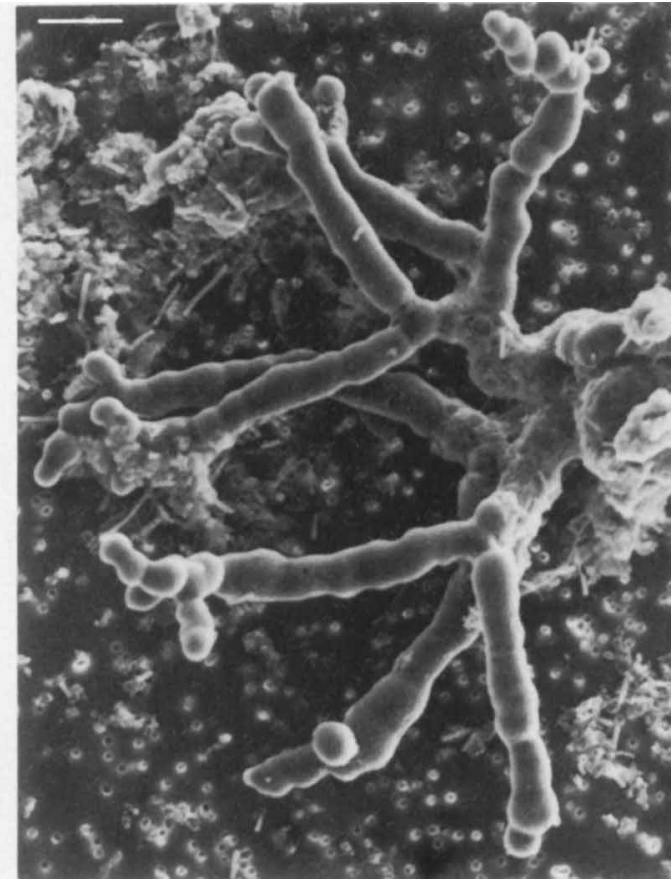

Fig. 6

Fig. 5. SEM micrograph of swollen spores and hyphae from a culture grown for $48 \mathrm{~h}$ under $15 \% \mathrm{CO}_{2}$ Bar, $10 \mu \mathrm{m}$.

Fig. 6. SEM micrograph of mycelium from a culture grown for $56 \mathrm{~h}$ under $20 \% \mathrm{CO}_{2}$. Bar, $10 \mu \mathrm{m}$.

The hyphae that developed from these spores were $2 \cdot 5-3 \cdot 0 \mu \mathrm{m}$ in diameter, and some swollen and deformed hyphae were observed (Fig. 5). The diameters of the hyphae and the spores were $20 \%$ and $12 \%$, respectively, greater than those in the control cultures.

Part of a mycelium grown for $56 \mathrm{~h}$ at an influent $\mathrm{CO}_{2}$ concentration of $20 \%$ is shown in Fig. 6 . The individual cells within the hyphae can be seen to have become swollen, causing the hyphae to have a 'bumpy' appearance. The diameter of the hyphae was 4.0-7.0 $\mu \mathrm{m}$. The diameters of the spores could not be measured because of difficulty in identifying them. Almost all the hyphal tips were severely deformed, indicating an adverse effect of high $\mathrm{CO}_{2}$ concentration on mycelial growth. There appeared to be an increase in the branching frequency near the hyphal tips. Fig. 7 shows hyphae grown for $88 \mathrm{~h}$ with an influent $\mathrm{CO}_{2}$ concentration of $20 \%$. The main difference in comparison to the mycelia harvested at $56 \mathrm{~h}$ was in the length of the hyphae, since linear growth had continued and the hyphal cross-sectional diameter remained constant. Hyphae from an $88 \mathrm{~h}$ culture are shown at a higher magnification in Fig. 8. The mycelial structure appeared to be of the aberrant form described by Pirt \& Callow (1959), Morton (1961) and Bent \& Morton (1963). Not only were the hyphae much deformed, but their cell wall was also punctured, an effect not observed in the cultures harvested at $56 \mathrm{~h}$.

The major results of the present study are summarized in Table 1 . There are several possible explanations for the effects observed. $P$. chrysogenum cultures exposed to high concentrations of $\mathrm{CO}_{2}$ consisted of swollen hyphae in which individual cells were identifiable by the bumpy surface of the cell walls (Figs 6-8). This suggests that conidiation occurred in these conditions. In typical submerged mycelial fermentations, conidiation would normally occur under adverse environmental conditions (Morton, 1961; Bent \& Morton, 1963; Righelato et al., 1968).

As $\mathrm{CO}_{2}$ concentration increased, so did the degree of hyphal swelling, suggesting that either high $\mathrm{CO}_{2}$ concentrations affected the membrane transport properties of the cell or the cells were subject to osmotic swelling. $\mathrm{CO}_{2}$ may alter cell membranes by affecting the fatty acid core, and 


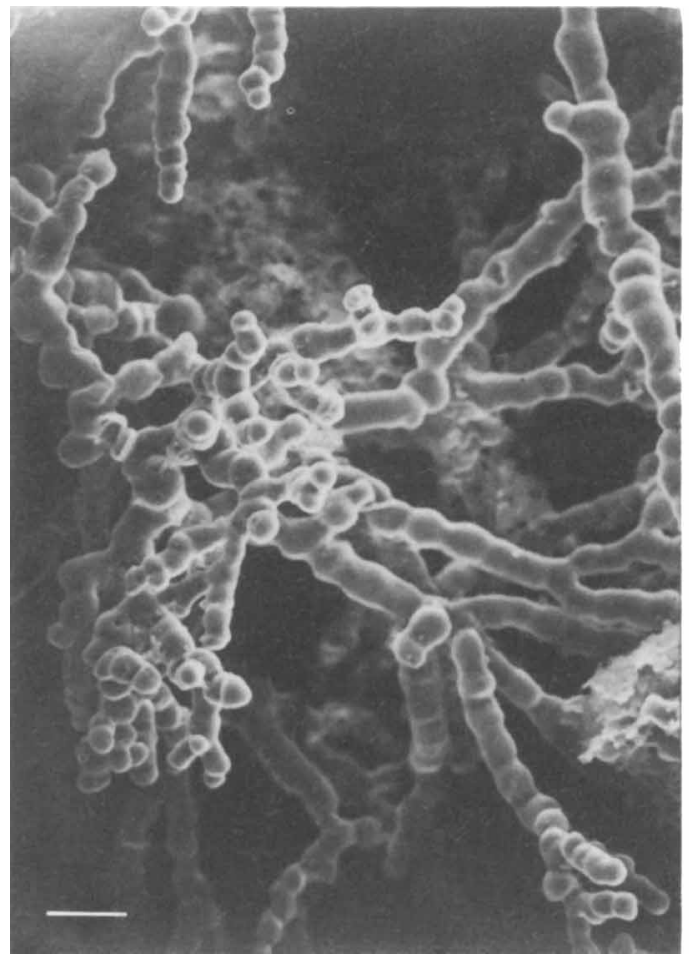

Fig. 7

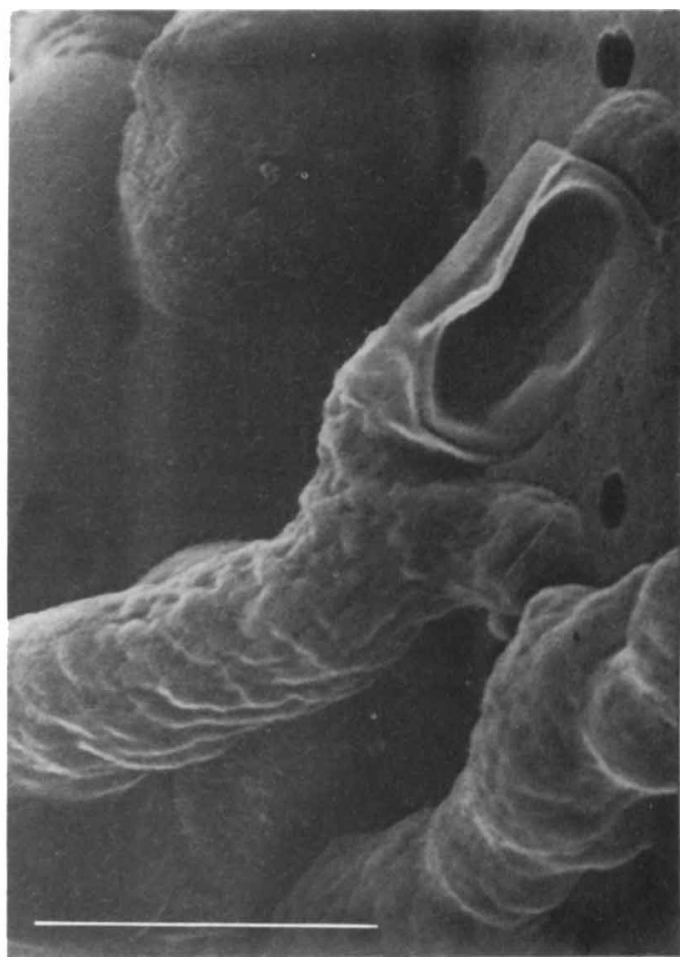

Fig. 8

Fig. 7. SEM micrograph of swollen hyphae from a culture grown for $88 \mathrm{~h}$ under $20 \% \mathrm{CO}_{2}$, Bar, $10 \mu \mathrm{m}$.

Fig. 8. SEM micrograph of a deformed and punctured hypha from a culture grown for $88 \mathrm{~h}$ under $20 \%$ $\mathrm{CO}_{2}$. Bar, $5 \mu \mathrm{m}$.

Table 1. Effect of $\mathrm{CO}_{2}$ on morphology of $P$. chrysogenum

Samples were taken from batch fermentations as described in Methods. Observations and measurements were made using SEM.

\begin{tabular}{|c|c|c|c|c|}
\hline $\begin{array}{c}\text { Influent } \mathrm{CO}_{2} \\
\text { concn }(\%)\end{array}$ & $\begin{array}{l}\text { Incubation } \\
\text { time }(\mathrm{h})\end{array}$ & $\begin{array}{l}\text { Hyphal diam. } \\
\qquad(\mu \mathrm{m})\end{array}$ & $\begin{array}{l}\text { Spore diam. } \\
\qquad(\mu \mathrm{m})\end{array}$ & Hyphal morphology \\
\hline 0.03 (air) & 48 & $2 \cdot 0$ & $5 \cdot 5$ & $\begin{array}{l}\text { Hyphae long, thin and diffuse (Fig. 2) } \\
\text { Tips smooth and rounded }\end{array}$ \\
\hline $8 \cdot 2$ & 48 & $2 \cdot 0-2 \cdot 5$ & NA & $\begin{array}{l}\text { Filamentous hyphae (Fig. 3) } \\
\text { Branching frequency of hyphae and tips (Fig. 4) } \\
\text { increased }\end{array}$ \\
\hline 15 & 48 & $2 \cdot 5-3 \cdot 0$ & $6 \cdot 0-7 \cdot 0$ & Some deformed, swollen hyphae (Fig. 5) \\
\hline 20 & 56 & $4 \cdot 0-7 \cdot 0$ & ND & $\begin{array}{l}\text { All hyphae severely swollen and deformed (Fig. 6) } \\
\text { Much increased branching frequency }\end{array}$ \\
\hline 20 & 88 & $4 \cdot 0-7 \cdot 0$ & ND & $\begin{array}{l}\text { Much increased branching frequency (Fig. 7) } \\
\text { Swollen hyphal walls punctured (Fig. 8) }\end{array}$ \\
\hline
\end{tabular}

NA, Not applicable; ND, not determined.

$\mathrm{HCO}_{3}^{-}$ions may affect the charge of the phospholipid head groups and proteins at the surface of the membrane (Alberts et al., 1983; Houslay \& Stanley, 1982). It is thus possible that $\mathrm{CO}_{2}$ caused the hyphal swelling by altering membrane transport processes.

Many fungi can grow in either a filamentous or a yeast-like form depending on environmental conditions (Stewart \& Rogers, 1983). Our results demonstrated that $P$. chrysogenum could grow in a yeast-like form in the presence of high $\mathrm{CO}_{2}$ concentrations, whereas at low to moderate $\mathrm{CO}_{2}$ 
concentrations, growth was predominantly filamentous with some yeast-like cells present, the proportion depending on $\mathrm{CO}_{2}$ concentration and culture age.

Chitin synthesis and the resulting chitin fibrils determine the shape or direction of mycelial growth (Stewart \& Rogers, 1983). Linear growth occurs as the chitin fibrils form a microfibril net around the circumference of the hyphae, whereas spherical growth results from the elimination of rearrangement of the chitin synthesis sites (Stewart \& Rogers, 1983). Possibly, as the concentration of $\mathrm{CO}_{2}$ was increased in the medium, the chitin synthesis sites on $P$. chrysogenum cells were reduced and spherical or yeast-like growth occurred as a result.

The branching frequency of $P$ : chrysogenum hyphae increased in the presence of added $\mathrm{CO}_{2}$ (Table 1). This increase in hyphal branches might be related to a higher transcellular electric current (Jaffe, 1981; Harold et al., 1985) under these conditions. A variety of fungi drive currents of protons which enter the apical zone of growing hyphal tips and leave distally (Jaffe \& Nuccitelli, 1974). An inward current of protons often precedes the outgrowth of new tips (Jaffe et al., 1974; Jaffe, 1981; Kropf et al., 1983, 1984; Harold et al., 1985). The $\mathrm{CO}_{2}$ in the gas mixtures sparged into the fermentation medium would form carbonic acid, which would be readily converted to $\mathrm{H}^{+}$and $\mathrm{HCO}_{3}^{-}$. In consequence, a higher quantity of protons would be present in the medium. The resulting higher endogenous electric currents could induce more growing hyphae, thus resulting in a higher branching frequency as compared to that of the control fermentation.

The authors are grateful to Mr Peter Bush for his help and consultation.

\section{REFERENCES}

AlberTs, B., Bray, D., Lewis, J., RAFF, M., RoberTS, K. \& WATSON, J. D. (1983). Molecular Biology of the Cell. New York: Garland Publishing Co.

BENT, K. J. \& Morton, A. G. (1963). Formation and nature of swollen hyphae in Penicillium and related species. Transactions of the British Mycological Society 46, 401-408.

Collinge, A. J., Miles, E. A. \& Trinci, A. P. J. (1978). Ultrastructure of hyphae of Penicillium chrysogenum Thom from colonies and chemostat cultures. Transactions of the British Mycological Society 70, 401-408.

Harold, F. M., Kropf, D. L. \& Caldwell, J. C. (1985). Why do fungi drive electric currents through themselves? Experimental Mycology 9, 183-186.

Ho, C. S. \& SMITH, M. D. (1986). Effect of dissolved carbon dioxide on penicillin fermentations: mycelial growth and penicillin production. Biotechnology and Bioengineering 28, 668-677.

Houslay, M. D. \& Stanley, K. K. (1982). Dynamics of Biological Membranes. New York: Wiley.

JAFFE, L. F. (1981). The role of ionic currents in establishing developmental pattern. Philosophical Transactions of the Royal Society B295, 553-566.

JAFFE, L. F. \& NuCCITELli, R. (1974). An ultrasensitive vibrating probe for measuring steady electrical currents. Journal of Cell Biology 63, 614-628

JAFFe, L. F., RobinSon, K. R. \& NucCitelli, R. (1974). Local cation entry and self electrophoresis as an intracellular localization mechanism. Annals of the New York Academy of Sciences 238, 372-389.

Kropf, D. L., Lupa, M. D. A., Caldwell, J. H. \& HAROLD, F. M. (1983). Cell polarity: endogenous ion currents precede and predict branching in the water mold Achlya. Science 220, 1385-1387.

Kropf, D. L., Caldwell, J. H., Gow, N. A. R. \& HAROLD, F. M. (1984). Transcellular ion currents in the water mold Achlya. Amino acid proton symport as a mechanism of current entry. Journal of Cell Biology 99, 486-496.

Miles, E. A. \& Trinci, A. P. J. (1983). Effect of pH and temperature on morphology of batch and chemostat cultures of Penicillium chrysogenum. Transactions of the British Mycological Society 81, 193-200.

Morton, A. G. (1961). The induction of sporulation in mould fungi. Proceedings of the Royal Society B153, 548-569.

PIRT, S. J. \& Callow, D. J. (1959). Continuous-flow culture of the filamentous mould Penicillium chrysogenum and the control of its morphology. Nature, London 184, 307-310.

Righelato, R. C., Trinci, A. P. J. \& Pirt, S. J. (1968). The influence of maintenance energy and growth rate on the metabolic activity, morphology and conidiation of Penicillium chrysogenum. Journal of General Microbiology 50, 399-412.

Stewart, P. R. \& Rogers, P. J. (1983). Fungal dimorphism. In Fungal Differentiation, pp. 267-313. Edited by J. E. Smith. New York: Marcel Dekker.

Trinci, A. P. J. \& Righelato, R. C. (1970). Changes in constituents and ultrastructure of hyphal compartments during autolysis of glucose-starved Penicillium chrysogenum. Journal of General Microbiology 60, 239-249. 